\title{
Vigotski: os conceitos espontâneos e científicos
}

\author{
Vigostski: los conceptos espontáneos y científicos \\ Vigotski: the spontaneous and scientific concepts
}

\section{Nandjara Novo Castro ${ }^{1}$}

\begin{abstract}
Resumo
O presente artigo apresenta o resumo do capítulo seis da obra A construção do pensamento e da linguagem, de Lev Semenovich Vigotski (2009). Ele faz parte de um projeto em desenvolvimento, na forma de pesquisa-ação, desenvolvido através de encontros com um grupo de professores na Escola Municipal de Ensino Fundamental Marechal Castelo Branco, localizada no Município de Jaguarão, Rio Grande do Sul. Sua leitura se torna extremamente relevante para os professores em formação, uma vez que o capítulo daquela obra explora, genuinamente, os conceitos espontâneos e os conceitos científicos acerca do desenvolvimento do processo de ensino e aprendizagem. $\mathrm{O}$ escopo deste trabalho está na necessidade de se repensar, juntamente com o grupo de professores da escola, o ensino de conteúdos, fundamentalmente voltados para a preocupação com o aprendizado pelos alunos. O projeto mencionado está em andamento e os encontros da pesquisa-ação continuam para que, futuramente, possamos nos apropriar de resultados mais precisos para fins de conclusão e aplicação.
\end{abstract}

Palavras-Chave: Vigotski; aprendizagem; conceitos espontâneos; conceitos científicos.

\section{Resumen}

Este artículo presenta el resumen del capítulo seis de la obra La construcción del pensamiento y del lenguaje, de Lev Semenovich Vigotski (2009). Hace parte de un proyecto en desarrollo, en forma de investigación-acción, desarrollado a través de encuentros con un grupo de profesores en la Escuela Municipal de Enseñanza Fundamental Marechal Castelo Branco, ubicada en el municipio de Jaguarão, Rio Grande do Sul. La lectura del capítulo es extremadamente relevante para los profesores en formación, ya que explora, genuinamente, los conceptos espontáneos y los conceptos científicos acerca del desarrollo del proceso de enseñanza y aprendizaje. El alcance de este trabajo está en la necesidad de repensar, junto con el grupo de profesores de la escuela, la enseñanza de contenidos, fundamentalmente orientados a la preocupación por el aprendizaje de los alumnos. El proyecto mencionado está en marcha y los encuentros de la investigación-acción continúan para que, en el futuro, podamos nos apropiar de resultados más precisos para fines de conclusión y aplicación.

Palabras claves: Vigostki; aprendizaje; conceptos espontáneos; conceptos científicos.

\begin{abstract}
This article aims to present the summary of chapter six of Lev Semenovich Vigotski's (2009) The construction of thought and language. He is part of a project under development in the form of the action-research methodology, developed through meetings with a group of teachers at the Marechal Castelo Branco Municipal Elementary School, located in the municipality of Jaguarão, Rio Grande do Sul. It's reading becomes extremely relevant for the teachers in formation, once this chapter of the book genuinely explores spontaneous and scientific concepts about the development of the teaching and learning process. The scope of this work is in the need of rethinking together with the group of school teachers the teaching of contents, fundamentally focused on the concern with the student's learning. The aforementioned project is underway and the action-research meetings continue so that in the future we can appropriate more accurate results for completion and application.
\end{abstract}

Keywords: Vigotski; learning; spontaneous concept; scientific concept.

\footnotetext{
${ }^{1}$ Especialista em Psicopedagogia Clínica e Institucional pela Universidade Federal do Pampa, Unipampa, Jaguarão; RS; Brasil; nand_castro@ @otmail.com
} 


\section{Introdução}

Objetiva-se, com o presente artigo não só a apresentação de uma síntese do mencionado capítulo seis da obra $A$ construção do pensamento e da linguagem de Lev Semenovich Vigotski (2009), mas, sobretudo, a elaboração do atrelamento do mesmo a pensamentos de outros autores que sustentam as mesmas concepções trazidas por ele, numa mescla ratificadora de sua importância.

Seu conteúdo vai ao encontro dos conceitos espontâneos e científicos, trazendo informações que valorizam e sustentam a problemática do projeto que está em andamento, como pesquisa-ação, na dialética de encontros com um grupo de professores da Escola Municipal Marechal Castelo Branco, e se debruça sobre a urgente necessidade de se repensar o ensino de conteúdos direcionados ao aprendizado pelos alunos.

Sua leitura se torna extremamente relevante não só para os professores já atuantes como para os que estão em formação, de vez que o capítulo explora, genuína e intensamente, estes conceitos acerca do desenvolvimento do processo de ensino e aprendizagem.

Vigotski é um autor que se preocupa, particularmente, com a escola, com o professor e com intervenções pedagógicas e, por isso, atrai os educadores, sobretudo ao valorizar o papel do professor na educação do sujeito. Para Vigotski, a atuação do professor é vista sob a ótica de que a escola tem muita importância para a definição e para o funcionamento psíquico do educando, uma vez que os estudantes fazem parte de um processo ininterrupto de construção, tendo na sua linguagem um poderoso dispositivo produtor de conceitos e de dialógica com o mundo.

\section{Os conceitos espontâneos e científicos}

Antes mesmo de iniciar a compreensão do desenvolvimento do conceito científico, que é o foco da temática do projeto no processo escolar, considero importante que sejam aclaradas, previamente, as diferenças entre esses dois conceitos - espontâneo e científico - de forma simples e resumida, para melhor percepção do leitor.

Para facilitar esse entendimento, Silva Júnior (2013, p. 119), nos brinda com uma melhor compreensão quando afirma que "Os conceitos espontâneos (ou cotidianos) são aqueles não relacionados ao ensino formal, adquiridos cotidianamente através da experiência concreta das crianças". 
No que diz respeito aos conceitos científicos, especifica que: "Por seu turno, representam os conhecimentos sistematizados, adquiridos nas interações escolarizadas [...] estão relacionados ao ensino formal [...]” (SILVA JÚNIOR, 2013, p. 119).

Há uma notória diferença, portanto, entre os dois conceitos, na medida em que o espontâneo, como o próprio nome expressa, nasce da experiência concreta e não formal, enquanto que o científico, também como o indica a nomenclatura, direciona-se especificamente aos conhecimentos obtidos de forma sistematizada e nas sendas das interações propiciadas pelo ensino formal.

Vigotski (2009) sustenta que o desenvolvimento dos conceitos científicos é de imensa importância, do ponto de vista das tarefas escolares, porque inicia a criança no universo da conceituação formal, mas, paralelamente, e em sentido contrário, muito pouco se sabe sobre esse assunto. Costas (2012, p. 17) contribui com Vigotski ao sinalizar que:

O indivíduo deixa de ser aquele que irá demonstrar esquemas cognitivos já estruturados, para se apresentar como um ser em construção, que está se apropriando de signos e de ferramentas culturais na sua relação mediada com os demais.

Vigotski (2009) evidencia que a primeira experiência de estudo sistemática desta questão foi proposta por J.I. Chif, que elaborou um estudo comparado do desenvolvimento dos conceitos espontâneos e científicos na idade escolar.

Nesta experiência, revelou-se que o crescimento contínuo e a manutenção de níveis elevados no pensamento científico e o crescimento acelerado do pensamento espontâneo levam, sistematicamente, ao aumento dos tipos de pensamento científico, que, por sua vez, aparecem no desenvolvimento do pensamento espontâneo e comprovam o papel predominante da aprendizagem no desenvolvimento escolar.

Vigotski (2009, p. 347), grandiosamente, esclarece que o desenvolvimento dos conceitos espontâneos da criança deve atingir certo nível para que ela possa apreender os científicos, e, neste mesmo grau de explicação, ele coloca o caminho que movimenta esses conceitos da seguinte forma:

Para efeito de clareza, poderíamos conceber esquematicamente o caminho do desenvolvimento dos conceitos espontâneos e científicos da criança sob a forma de duas linhas de sentidos opostos, uma das quais se projetando de cima para baixo, atingindo um determinado nível no ponto em que a outra se aproxima ao fazer o movimento de baixo para cima. Se designássemos convencionalmente como inferiores as propriedades do conceito mais simples, mais elementares, que amadurecem mais cedo, designando como superiores aquelas propriedades mais complexas, vinculadas à tomada de consciência e à arbitrariedade e que se desenvolvem mais tarde, poderíamos dizer convencionalmente que o conceito espontâneo da criança se desenvolve de baixo para cima, das propriedades mais 
elementares e inferiores às superiores, ao passo que os conceitos científicos se desenvolvem de cima para baixo, das propriedades mais complexas e superiores para as mais elementares e inferiores. Esta diferença esta vinculada à referida relação distinta dos conceitos científico e espontâneo com o objeto (V1GOTSKI, 2009, p. 347).

O trajeto do desenvolvimento do conceito científico nas ciências sociais acontece através das circunstâncias do processo educacional, que estabelece uma maneira original de colaboração sistemática entre o professor e o aluno. Nesse processo ocorre o amadurecimento das funções psicológicas superiores. E, nessa colaboração entre professor e aluno, é que reside o momento central do sistema educativo que corresponde à situação em que os conhecimentos são transmitidos à criança de forma sistemática. Veja-se:

\begin{abstract}
A essa colaboração original entre a criança e o adulto - momento central do processo educativo paralelamente ao fato de que os conhecimentos são transmitidos à criança em um sistema - deve-se o amadurecimento precoce dos conceitos científicos e o fato de que o nível de desenvolvimento desses conceitos entra na zona das possibilidades imediatas em relação aos conceitos espontâneos, abrindo-lhes caminho e sendo uma espécie de propedêutica do seu desenvolvimento (VIGOTSKI, 2009, p. 244).
\end{abstract}

Os dados desta pesquisa revelam, também, que a fragilidade dos conceitos espontâneos aparece na incapacidade para o raciocínio, para uma operação voluntária com esses conceitos, de maneira que sua aplicação incorreta ganha validade. A debilidade do conceito científico é o seu verbalismo, que aparece como principal perigo no caminho do desenvolvimento destes conceitos.

Já em outra situação da pesquisa, o quadro muda, e, nele, o verbalismo é substituído pela concretização, o que aparece, também, no desenvolvimento dos espontâneos, igualandose aos desvios do desenvolvimento da criança.

A partir de estudos sobre o processo da formação de conceitos, Vigotski (2009) destaca que um conceito é mais do que a soma de alguns elos associativos formados pela memória. É mais do que um hábito mental e não pode ser aprendido por memorização. Em termos psicológicos, o conceito é um ato de generalização e, psicologicamente concebido, progride como significado da palavra.

Então, para o autor, o processo do significado das palavras precisa do desenvolvimento de uma sequência de funções como a atenção voluntária, memória lógica, abstração, comparação e discriminação. E todos esses processos não podem ser somente memorizados ou assimilados. Neste caso, o conceito aprendido de forma pronta pelo aluno na aprendizagem e assimilado, da mesma forma como se assimila uma habilidade intelectual qualquer, é inconsistente do ponto de vista psicológico. O professor que segue essa linha não costuma obter, como resultado, a apreensão dos conceitos pelo aluno. Apenas conseguirá uma 
assimilação vazia das palavras, consistente num verbalismo puro e simples que somente estimula e imita a existência dos conceitos na criança. Vigotski (2009, p. 247) enfatiza que:

[...] a criança não assimila o conceito, mas a palavra capta mais de memória que de pensamento e sente-se impotente diante de qualquer tentativa de emprego consciente do conhecimento assimilado. No fundo, esse método de ensino de conceitos é a falha principal do rejeitado método puramente escolástico de ensino, que substitui a apreensão de conhecimento vivo pela apreensão de esquemas verbais mortos e vazios.

O autor esclarece que é complexo e difícil o processo psicológico interior que ocorre entre o momento em que a criança por primeiro tem conhecimento do novo conceito e o instante em que a palavra e o conceito se fundem, sendo devidamente apropriados pela criança, porque a plena compreensão da nova palavra não é imediata, mas, ao contrário, tem seu desenvolvimento gradual a partir de uma noção vaga e superficial, até que culmine com a efetivação de uma compreensão conclusiva.

O caminho entre o primeiro momento em que a criança trava conhecimento com o novo conceito e o momento em que a palavra e o conceito se tornam propriedade da criança é um complexo processo psicológico interior, que envolve a compreensão da nova palavra que se desenvolve gradualmente a partir de uma noção vaga, a sua aplicação propriamente dita pela criança e sua efetiva assimilação apenas como elo conclusivo (VIGOTSKI, 2009, p. 250).

Vigotski (2009) destaca que os conceitos científicos não se desenvolvem exatamente como os espontâneos, que o processo do seu desenvolvimento não repete as vias de desenvolvimento dos conceitos espontâneos e que a investigação experimental, apresentada em seu capítulo, tem o propósito de confirmar de fato esta afirmação e explicar de forma clara as diferenças que existem entre esses dois processos.

O autor atesta que tudo se resume em entender que a formação dos conceitos científicos, na mesma medida dos espontâneos, não termina, mas apenas começa no momento em que a criança assimila pela primeira vez um significado ou termo novo para ela, que é vínculo de conceito científico.

Após as investigações, Vigotski (2009) assinala que há uma terceira hipótese, além das duas que se baseiam nos conceitos científicos. Numa, esses conceitos repetem em seu desenvolvimento as vias de formação dos espontâneos e, na outra, os conceitos científicos não têm nada em comum com o desenvolvimento dos espontâneos. Esta terceira hipótese é a que determina as relações verdadeiras, complexas e bilaterais entre os conhecimentos espontâneos e científicos.

Para que se possa descobrir esta terceira incógnita, não existe outro caminho a não ser a comparação entre os dois conceitos como caminho do desconhecido ao conhecido. A 
delimitação de ambos é condição prévia para esse estudo comparado dos conceitos e estabelecimento das suas verdadeiras relações. Relações em geral, e, mais ainda, aquelas relações sumamente complexas, só podem existir entre objetos que não coincidem entre si, uma vez que não é possível nenhuma relação do objeto consigo mesmo.

A relação dos conceitos científicos com a experiência pessoal da criança é diferente da relação dos conceitos espontâneos. Eles surgem e se constituem no processo de aprendizagem escolar por via inteiramente diferente que no processo de experiência pessoal da criança. As motivações internas, que levam a criança a formar conceitos científicos, também são inteiramente distintas daquelas que levam o pensamento infantil à formação de conceitos espontâneos (VIGOTSKI, 2009, p. 263).

Em seus relatos, Vigotski (2009) expressa que criança percebe a capacidade para uma sequência geral de operações lógicas, quando elas aparecem através do fluxo espontâneo do seu próprio pensamento, porém, não é capaz de fazer operações completamente similares, quando suas execuções são exigidas não de forma espontânea, mas de um jeito intencional e arbitrário.

A criança compreende as causas e as relações mais simples, porém não tem consciência dessa compreensão. Espontaneamente ela usa de maneira correta a conjunção "porque", mas não consegue aplicá-la de modo intencional e arbitrário. Desse modo, por via esses dois fenômenos do pensamento infantil, a nãoconsciência de tal vínculo e a não-arbitrariedade, a compreensão inconsciente e a aplicação espontânea (VIGOTSKI, 2009, p. 274).

O processo de escolarização específico é preciso para que se possam dominar as funções superiores, pois se dominam tais funções na medida em que a criança se intelectualiza. Costas (2012, p. 75) elucida ao afirmar:

É inquestionável, então, a relevância da ação docente nos processos educacionais, em especial no que se refere à aprendizagem e ao desenvolvimento, aspectos basilares da instrução formal e intimamente ligados à formação dos conceitos científicos.

Seguindo esta mesma linha do processo de escolarização, Vigotski (2009) aponta, também, que, na atenção e na memória, o aluno não só percebe a capacidade para a tomada de consciência e a arbitrariedade, mas também que o desenvolvimento dessa capacidade é o responsável por constituir o conteúdo principal de toda uma idade escolar. Neste processo escolar, o desenvolvimento da consciência passa por todo um processo e se modifica a cada nova fase.

Segundo o autor, a lei que rege o desenvolvimento baseia-se na premissa de que a tomada de consciência e a assimilação não são específicas somente da fase superior de desenvolvimento de alguma função. Elas aparecem mais adiante e antecedidas do estágio de 
funcionamento inconsciente e não arbitrário. Contudo, para se tomar consciência tem que haver o que deve ser conscientizado e, para assimilar, é imprescindível ter aquilo que deve ser subordinado à própria vontade. Não obstante, Vigotski (2009) ressalta que o caminho para um novo tipo de apreensão interior significa o acesso para um tipo superior de atividade psíquica interior pois, entender as coisas diferenciadamente, significa ganhar outras capacidades de agir com relação a elas.

Costas (2012, p. 161), de seu turno, prenuncia que "A tomada de consciência é algo que vai se tornando cada vez mais ampliado, porque é uma forma de reflexão do homem que experencia mudanças radicais".

Vigotski (2009) coloca que o problema dos conceitos científicos tem a ver com o ensino e o desenvolvimento, pois os conceitos espontâneos tornam possível o surgimento desses conceitos a partir da aprendizagem que, por sua vez, é a razão para o seu desenvolvimento. Sendo assim, irá gerar possibilidades que se realizam no processo escolar, se identificando com a maturação. Nessa direção, o autor nos ajuda a compreender este pensamento ao sustentar que:

[...] já no limiar da idade escolar, a criança dispõe de uma atenção e uma memória relativamente maduras. Já tem o que deve conscientizar e o que deve assimilar. Fica compreensível por que as funções conscientizadas e arbitrárias da memória e da atenção são projetadas ao centro nessa idade (VIGOTSKI, 2009, p. 287).

É esclarecido na obra que a pedagogia deve considerar as características autônomas do pensamento da criança como um limite inicial inferior que define a probabilidade da aprendizagem e que, ao despertar na criança outras potencialidades do pensamento, será possível uma nova aprendizagem.

Vigotski (2009) elucida que, diante de suas investigações, todo processo de aprendizagem e desenvolvimento não é independente ou igual, mas existem relações complexas entre eles.

Em suas investigações sobre linguagem e escrita, Vigotski (2009) relata que a escrita é uma função específica da linguagem e conclui que os motivos que estimulam a criança para a linguagem escrita ainda são pouco acessíveis para ela, no momento em que apenas começa a estudar a escrita. $\mathrm{Na}$ linguagem escrita, ela mesma é forçada a criar situações, representá-las no pensamento e agir voluntariamente. Ele destaca que cabe o entendimento de que a linguagem externa aparece no desenvolvimento antes da interna e que a escrita é a janela para a linguagem interior. Em seu entendimento, a linguagem interior é abreviada ao máximo e a escrita se desenvolve ao máximo, formalmente mais acabada que a fala, e leva a criança a agir de maneira mais intelectual e a ter mais consciência do próprio processo de fala. Segundo o autor, na escola a criança aprende graças à 
escrita e à gramática, além de tomar consciência do que faz e atuar por conta própria com suas habilidades.

Toda a aprendizagem escolar, de acordo com Vigotski (2009), gira em torno das novas formações básicas da idade escolar, ou seja, da tomada de consciência e a apreensão.

Já o desenvolvimento da base psicológica da aprendizagem, de cada disciplina, não antecede o seu início, mas se realiza num vínculo interior com ele, no processo do seu desenvolvimento.

Neste contexto, a tomada de consciência e a apreensão preenchem o primeiro plano do desenvolvimento e, da mesma forma, na aprendizagem da escrita e gramática. Contudo, o desenvolvimento não se subordina ao programa escolar: ele tem uma lógica própria e as diferentes matérias de ensino interagem no processo de desenvolvimento da criança. $\mathrm{O}$ autor explica assim:

Existe um processo de aprendizagem; ele tem a sua estrutura interior, a sua sequência, a sua lógica de desencadeamento; e no interior, na cabeça de cada aluno que estuda, existe uma rede subterrânea de processos que são desencadeados e se movimentam no curso da aprendizagem escolar e possuem a sua lógica de desenvolvimento (VIGOTSKI, 2009, p. 325).

Neste ímpeto Vigotski (2009) nos diz que uma das atividades fundamentais da psicologia da aprendizagem escolar é desvendar esta lógica interna de processos de desenvolvimento provocado por um ou outro processo de aprendizagem.

Conforme Vigotski (2009), o nível de desenvolvimento atual está relacionado ao que a criança consegue resolver sozinha e o nível de desenvolvimento imediato está relacionado ao nível que ela atinge ao resolver os problemas sem autonomia, com a colaboração de outra pessoa e, este nível, conclui, através de pesquisas, que é mais importante do que o atual, pois está ligado à dinâmica do desenvolvimento intelectual e do aproveitamento. E, uma vez que a criança seja orientada, ajudada através do processo de colaboração, sempre poderá fazer mais e resolver atividades mais complexas do que quando atua sem orientação. Ele destaca:

O fundamental na aprendizagem é justamente o fato de que a criança aprende o novo. Por isso a zona de desenvolvimento imediato, que determina esse campo das transições acessíveis à criança, é a que representa o momento mais determinante na relação da aprendizagem com o desenvolvimento (VIGOTSKI, 2009, p. 331).

O autor afirma que a pedagogia deve se colocar no amanhã do desenvolvimento da criança e não no ontem, e, neste sentido, ela conseguirá libertar, no caminho da aprendizagem, todo aquele processo de desenvolvimento que hoje está no nível de desenvolvimento imediato, e a disciplina formal de cada matéria escolar é o lugar em que se efetua a influência da aprendizagem sobre o desenvolvimento. Complementa, também, que a 
diferença de nível entre um conceito e outro em cada criança, bem como a força e a fraqueza dos conceitos científicos e espontâneos são diferentes em cada uma delas. Destaca:

Aquilo em que é forte o conceito de "irmão", que percorreu um longo caminho de desenvolvimento e esgotou grande parte do seu conteúdo empírico, acaba sendo o lado fraco do conceito científico e, ao contrário, aquilo em que é forte o conceito científico, como o conceito da lei de Arquimedes ou da "exploração", acaba sendo o ponto fraco do conceito espontâneo (VIGOTSKI, 2009, p. 346).

Vigotski (2009) explica que o desenvolvimento do conceito espontâneo da criança deve atingir um nível preciso para que ela possa aprender o conceito científico e tomar consciência dele. O conceito espontâneo, que passou de baixo para cima de forma histórica e longa, abriu caminho para que o científico continuasse a se desenvolver de cima para baixo, criando uma sequência de estruturas fundamentais para o desencadeamento de propriedades inferiores e elementares do conceito.

$\mathrm{O}$ autor assegura que a tomada de consciência e a arbitrariedade dos conceitos, não completamente desenvolvidas dos conceitos espontâneos do aluno, estão localizadas em sua totalidade na zona do seu desenvolvimento imediato, revelando e tornando-se eficazes na colaboração com o adulto.

Coloca-nos, também, que, indiscutivelmente, todo o conceito é uma generalização e que os conceitos não estão um ao lado do outro ou um sobre o outro, sem vínculo e sem qualquer relação. A generalização favorece a percepção imediata do real e ocorre pela via do estabelecimento de vínculos complexos, de dependência, e relações com objetos representados no conceito e a realidade restante. Entretanto, Vigotski (2009) explicita que a generalidade (a sua diferenciação) não corresponde com a estrutura da generalização e suas diferentes etapas, e que, com isso, não coincidem de forma imediata e direta com a estrutura da generalização, mas que, contudo, não são diferentes e não se desvinculam entre si. Para complementar Vigotski (2009, p. 361) destaca que:

[...] não há coincidência entre as relações de generalidade e estrutura de generalização, mas essa falta de coincidência não é absoluta e só ocorre em uma determinada parte: embora nas diferentes estruturas da generalização possa haver conceitos de generalidade única e, ao contrário, na mesma estrutura da generalização possam coincidir conceitos de estrutura vária, ainda assim essas relações de generalidade são diferentes em cada estrutura da generalização: tanto onde são logicamente idênticas quanto onde são diferentes.

$\mathrm{O}$ autor nos indica que, diante disto, estamos numa lei geral onde se encontra o caminho para os estudos das relações genéticas e psicológicas entre o geral e o particular nos 
conceitos da criança, onde há relações de generalidade para cada etapa da generalização e que as estruturas dispõem, em ordem genética, os conceitos particulares e gerais, realizando movimentos do geral ao particular e vice-versa. Assim, o desenvolvimento dos conceitos vem a ser dessemelhante em cada etapa do desenvolvimento dos significados, em decorrência da estrutura de generalização atuante nessa etapa.

Vigotski (2009) conclui que, as relações de generalidade, que mudam a cada nova estrutura de generalização, causam alterações em todas as operações de pensamento disponíveis para a criança em um determinado estágio. Contudo, de acordo como se desenvolvem as relações de generalidade, aumenta a independência do conceito em relação à palavra, sentido e expressão, surgindo uma liberdade cada vez maior.

Vigotski (2009) elucida que a tomada de consciência, ou seja, a generalização, que provém na sua compreensão, como caso particular de qualquer sistema de aprendizado específico, conduz à possibilidade de ação arbitraria em qualquer sistema.

Pode-se dizer que a criança constrói uma nova estrutura de generalização, primeiramente com poucos conceitos frequentemente recuperados, como no processo da aprendizagem em que já domina essa nova estrutura e, por conta disto, reconstrói e modifica a estrutura de todos os conceitos prévios. Vigotski (2009, p. 375) aclara seu raciocínio quando explica que:

[...] a nova estrutura de generalização, à qual a criança chega no processo de aprendizagem, cria a possibilidade para que os seus pensamentos passem a um plano novo e mais elevado de operações lógicas. Ao serem incorporados a essas operações de pensamento de tipo superior em comparação com o anterior, os velhos conceitos se modificam por si mesmos em sua estrutura.

Para Vigotski (2009), o sentido do conceito se baseia na lei de equivalência dos conceitos e presume o possível movimento de uns conceitos a outros, em que a longitude (generalização), específica de um determinado conceito, e a latitude (generalidade), sua proporção de generalidade que lhe estabelece o conteúdo do ato de pensamento e o seu relacionamento com o objeto, podem ser manifestados pela ligação dos eventos de outra longitude e outra latitude, bem como de outra proporção de generalidade, contendo outras ações de pensamento e outra espécie de amplitude do objeto e que, na união, são proporcionais a certo conceito, pela latitude e pela longitude. Ele contempla essa ideia afirmando que:

Entretanto, sabe-se que a cada estrutura da generalização corresponde o seu sistema de relações de generalidade, uma vez que as generalizações de estrutura diferente não podem encontrar-se em diferentes sistemas de relações de generalidade entre si. 
Logo, a cada estrutura da generalização corresponde também o seu sistema específico de operações lógicas de pensamento, possíveis nessa estrutura. Essa lei das mais importantes de toda a psicologia dos conceitos significa, em essência, a unidade da estrutura e da função do pensamento, a unidade do conceito e das operações possíveis para ele (VIGOTSKI, 2009, p. 379).

\section{Conclusão}

É certo que tudo que vimos até aqui está profundamente voltado à Teoria HistóricoCultural atribuída por Vigotski e, as relações entre esses conceitos com o desenvolvimento e a aprendizagem, são aspectos muito importantes dos estudos do autor.

O seu postulado básico está intimamente ligado à concepção de que o desenvolvimento se dá de fora para dentro, ou seja, por causa da importância da cultura, da importância da imersão do homem no mundo e em volta dele. E por esta concepção ser tão importante para ele é que a aprendizagem tem destaque extremamente valoroso na definição dos caminhos do desenvolvimento, pois é, afinal, através da aprendizagem que o sujeito se desenvolve.

E é indene de dúvida que a cultura afeta o "como" pensamos e o "que" pensamos, de forma que cada cultura tem o seu próprio impacto.

O conhecimento, por sua vez, também depende da experiência social e o desenvolvimento não pode ser separado desse contexto.

Por essas indiscutíveis razões, os adultos têm um papel muito importante no desenvolvimento dos educandos, através do que ensinam e orientam, conforme nos apresenta o autor em destaque.

\section{Referências}

COSTAS, Fabiane Adela Tonetto. Formação de conceitos em crianças com necessidades educacionais especiais: contribuições da Teoria Histórico-Cultural. Santa Maria: Editora UFSM, 2012. 200 p.

SILVA JUNIOR, Bento Selau da. Fatores associados à conclusão da educação superior por cegos: um estudo a partir de L. S. Vigotski. 2013. 288 f. Tese (Doutorado em Educação) Universidade Federal de Pelotas, Pelotas, 2013.

VIGOTSKI, L. S. A construção do pensamento e da linguagem. São Paulo: Martins Fontes, 2009. 